\title{
Estoques de carbono e nitrogênio sob diferentes condições de manejo de um Argissolo Vermelho Amarelo, cultivado com milho doce nos tabuleiros costeiros de Sergipe
}

\section{Carbon and nitrogen stocks under different management conditions of a yellow-red ultisol, cultivated with sweet corn in Sergipe coastal tablelands}

\author{
Wellma Nascimento Pedra ${ }^{1 *}$; Alceu Pedrotti²; Tácio Oliveira Silva²; \\ Fabrício Lopes de Macedo $^{3}$; Maria Isidória Silva Gonzaga²
}

\begin{abstract}
Resumo
O objetivo deste estudo foi analisar o efeito de diferentes sistemas de cultivo com plantas de cobertura em sucessão ao milho doce (Zea mays L.) no estoque de $\mathrm{C}$ e $\mathrm{N}$ do solo, em experimento de longa duração conduzido em um Argissolo Vermelho-Amarelo nos Tabuleiros Costeiros no Estado de Sergipe. Utilizou-se um sistema de faixas experimentais sob parcelas subdivididas, compostos por 12 tratamentos que associam três manejos de solos (parcelas), compostas por sistema de cultivo convencional (CC), cultivo mínimo (CM) e o sistema plantio direto $(\mathrm{PD})$ e, como subparcelas, quatro plantas, sendo duas comerciais [amendoim (Arachis hypogeae), feijão (Phaseolus vulgaris) e duas de cobertura: [guandu (Cajanus cajan) e crotalária (Crotalaria juncea)], com três repetições. No Plantio Direto houve um maior incremento do carbono orgânico total em comparação aos outros sistemas de manejo.Os sistemas Plantio Direto e Cultivo Mínimo foram os que mais contribuíram para o aumento dos teores de nitrogênio total no solo. As plantas de cobertura feijão, amendoim e guandu proporcionaram maiores estoques de carbono, dentro do sistema Plantio Direto. No Cultivo Mínimo o guandu proporcionou maiores estoques de nitrogênio. Os sistemas Plantio Direto e Cultivo Mínimo apresentaram os maiores estoques de carbono e nitrogênio respectivamente, em comparação ao Cultivo convencional, contribuindo para uma melhor sustentabilidade agrícola.
\end{abstract}

Palavras-chave: Carbono, nitrogênio, plantas de sucessão

\begin{abstract}
This study was carried out in a long term experiment and aimed to evaluate the effects of different tillage systems associated with cover crops following sweet corn (Zea mays L.) cultivation on soil C and $\mathrm{N}$ stocks. The soil was a red-yellow Ultisol, characteristic of the coastal tableland in the estate of Sergipe. Experimental bands over a split plot scheme were set up with 12 treatments: three management systems (conventional tillage (CC), reduced tillage (CM) and, No-tillage (PD), in the plots, and four cover crops (peanut (Arachis hypogeae), common bean (Phaseolus vulgaris), pigeon pea (Cajanus cajan) and, crotalaria (Crotalaria juncea), in the subplots, with three replications. The highest soil organic carbon input was observed on the No-tillage system as compared to the other tillage systems.
\end{abstract}

\footnotetext{
Bióloga, Mestre em Agroecossistemas pela Universidade Federal de Sergipe, UFS, Sergipe, SE. E-mail: wellmabio@yahoo.com.br

2 Engenheiros Agrônomos, D.Sc., Profs. do Dept ${ }^{\circ}$. de Engenharia Agronômica, UFS, Sergipe, SE. E-mail: alceupedrotti@hotmail. com; taccios@hotmail.com; mariaisisilva@gmail.com

3 Eng $^{\circ}$ Agr $^{\circ}$, Mestre em Agroecossistemas pela UFS, Sergipe, SE. E-mail: fabriciolmacedo@hotmail.com

* Autor para correspondência
} 
As far as N content is concerned, both No-tillage and reduced tillage systems contributed the most. Notillage system associated with cover crops such as Common bean, Peanut and Pigeon pea contributed to a higher soil organic carbon stock while higher N stock was observed when Pigeon pea was associated with reduced tillage system. No-tillage and reduced tillage systems presented higher $\mathrm{C}$ and $\mathrm{N}$ stocks, respectively, when compared to conventional tillage, improving agriculture sustainability.

Key words: Carbon, nitrogen, succession plants

\section{Introdução}

No ciclo do carbono terrestre, os solos contêm a maior fração deste elemento, em relação à vegetação e à atmosfera. Conseqüentemente, o solo é considerado o maior reservatório e o principal sumidouro de carbono. Este carbono é considerado seqüestrado pelo relativo longo período de tempo que possa residir nos solos e assim ficar impedido de voltar para a atmosfera (SWIFT, 2001).

$\mathrm{Na}$ iminência de mudanças climáticas de controversa reversibilidade (MEEHL et al., 2007), a importância do conhecimento dos estoques de carbono em diferentes classes de solos está ligada à tentativa de avaliar o que poderá ser perdido ou aportado, caso ocorram mudanças no uso da terra (LAL, 2004).

Essas mudanças são ocasionadas pela adoção de práticas intensificadoras da decomposição ou mineralização da matéria orgânica (MO) ou de aumentos de temperatura como conseqüência das mudanças climáticas globais (LAL, 2004) e, mais recentemente, o que isto pode representar em termos de serviços ambientais de estocagem de carbono pelos solos (HAVSTAD et al., 2007).

O estoque de carbono de um solo sob vegetação natural representa o balanço dinâmico entre a adição de material vegetal morto e a perda pela decomposição ou mineralização. A qualidade do carbono da vegetação depende muito do clima (principalmente, temperatura do ar e chuvas), do tipo de vegetação e da fertilidade do solo (solos férteis resultam em plantas maiores que contêm mais carbono a ser depositado no solo). Os processos de transformação do carbono são fortemente influenciados pelo clima, tipo e qualidade da $\mathrm{MO}$ e suas associações químicas e fisico-químicas com os componentes minerais do solo (MACHADO, 2005).

Os estudos de avaliação de estoques de carbono (EC) e estoques de nitrogênio (EN) em solos têm sido feitos com o objetivo de se conhecer o tamanho do compartimento solo como armazenador de carbono e nitrogênio, imprescindível no auxílio ao levantamento dos conteúdos de carbono orgânico seqüestrados nos ecossistemas terrestres (LORENZ et al., 2007).

A pesquisa tem mostrado que, indubitavelmente, a manutenção do estoque de carbono no solo cultivado é intrínseco ao manejo dispensado ao solo e às culturas, que também interfere, na qualidade dos recursos hídricos inseridos no contexto das bacias hidrográficas dos ecossistemas envolvidos. Para exemplificar, somente a conversão de ecossistemas naturais para agricultura pode corresponder a perdas superiores a $60 \%$ do estoque de matéria orgânica em solos temperados e superar $75 \%$ do estoque original em solos tropicais, implicando, portanto, em significativa emissão de gás carbônico para a atmosfera (LAL, 2004).

No Brasil, em sistemas de manejo de solo baseados no preparo convencional com intenso revolvimento de solo, normalmente, a perda do estoque original da matéria orgânica do solo, em solo não cultivado e em mata natural, pode atingir $50 \%$ em períodos que variam de 15 a 23 anos (BAYER et al., 2003).

O preparo do solo, especialmente o convencional, com arados e grades, aumenta a oxidação do $\mathrm{C}$ e a mineralização do $\mathrm{N}$ pela incorporação dos resíduos, pela quebra dos agregados e pelo aumento da 
aeração do solo. Por outro lado, sistemas de preparo como o plantio direto, que diminuem a incorporação dos resíduos e a ruptura dos agregados, podem conservar ou aumentar os estoques de $\mathrm{C}$ e N (ALKAISI; YIN, 2005).

$\mathrm{O}$ acúmulo anual de $\mathrm{C}$ em solos cultivados nos sistemas de plantio direto para todo o Brasil foi estimado em $-0,5$ a 0,9 tha $^{-1}$ ano $^{-1}$, com valor médio de 0,65 tha $^{-1}$ ano $^{-1}$, quando comparado ao plantio convencional (BERNOUX et al., 2006). O acúmulo de carbono no solo está intimamente associado à utilização do sistema plantio direto. Os solos brasileiros acumulam, em média, $0,5 \mathrm{Mg} \mathrm{C}^{-1} \mathrm{ano}^{-}$ ${ }^{1}$ (CERRI et al., 2007).

O sistema plantio direto pode também reduzir as emissões de outros gases $\left(\mathrm{N}_{2} \mathrm{O}, \mathrm{NO}, \mathrm{CH}_{4}\right)$, com adoção de rotações de culturas que incluam leguminosas e otimização do uso de fertilizantes nitrogenados, além de manter a sustentabilidade do sistema evitando a necessidade de expansão da agricultura para novas áreas (QUEIROZ NETO, 2006).

Esse sistema pode ser considerado uma atividade com potencial para seqüestrar carbono no solo. Com o revolvimento somente na linha de plantio, a quantidade e manejo dos resíduos culturais depositados, as culturas envolvidas no sistema de rotação (LOVATO et al., 2004; DIEKOW et al., 2005) podem favorecer o acúmulo de $\mathrm{C}$ com a proteção física da MOS, dependendo das condições climáticas e do tipo de solo (BAYER et al., 2002).

Juntamente com os sistemas de manejo do solo, a introdução de leguminosas como plantas de cobertura de solo é uma prática que tem aumentado o fornecimento de nitrogênio e a produtividade de grãos e biomassa das culturas. Adicionalmente aos aspectos relacionados ao rendimento das culturas, essas espécies têm aumentado os estoques de matéria orgânica e proporcionado melhorias em várias propriedades químicas, físicas e biológicas do solo, principalmente quando associadas a sistemas de preparo sem revolvimento, ou com mínima mobilização do solo (BAYER et al., 2003).
O objetivo deste estudo foi analisar o efeito de diferentes sistemas de cultivo (Sistema plantio direto, cultivo mínimo e cultivo convencional) com plantas de cobertura: [Crotalária (Crotalaria juncea), Guandu (Cajanus cajan), Feijão (Phaseolus vulgaris) e Amendoim (Arachis hypogea)] em sucessão ao milho doce (Zea mays L.) no estoque de $\mathrm{C}$ e $\mathrm{N}$ do solo, em experimento de longa duração conduzido em um Argissolo Vermelho-Amarelo nos tabuleiros costeiros do estado de Sergipe.

\section{Material e Métodos}

Área de estudo

O estudo foi realizado no período de outubro de 2009 a janeiro de 2010 na Estação Experimental Campus Rural do Departamento de Engenharia Agronômica (DEA), da Universidade Federal de Sergipe (UFS), localizado na porção central da região fisiográfica do Litoral, no município de São Cristóvão-SE, a $15 \mathrm{~km}$ de Aracaju, cujas coordenadas geográficas são $10^{\circ} 19^{\prime} \mathrm{S}$ de latitude, $36^{\circ} 39^{\prime} \mathrm{O}$ de longitude, com altitude de $22 \mathrm{~m}$ acima do nível médio do mar, em solo classificado como Argissolo Vermelho-Amarelo (antigo Podzólico Vermelho- Amarelo - PV), conforme Embrapa Solos (2006). A região possui clima, de acordo com a classificação de Köppen, do tipo As',tropical chuvoso com verão seco e pluviometria em torno de $1200 \mathrm{~mm}$ anuais, com chuvas concentradas nos meses de abril a setembro e temperatura média anual de $22^{\circ} \mathrm{C}$.

O experimento é conduzido anualmente desde o ano de 2001, avaliando o comportamento dos sistemas de manejo: cultivo convencional - CC (composto de aração com arado de disco e duas gradagens, com grade niveladora de discos), cultivo mínimo - CM (composto de 1 ou 2 gradagens com grade niveladora de discos, sendo que a segunda gradagem somente é realizada quando há incidência considerável de plantas invasoras) e plantio direto - PD (consistindo do não revolvimento do solo), que foram realizados antes do plantio do milho 
doce anualmente e cultivo de plantas leguminosas em sucessão à cultura do milho doce (Zea mays L.) variedade Biomatrix BM 3061.

As plantas de leguminosas utilizadas todos os anos em sucessão ao milho doce (Zea mays L.) foram: comerciais: feijão (Phaseolus vulgaris) e amendoim (Arachis hipogeae); de cobertura: guandu (Cajanus cajan) e crotalária (Crotalaria juncea). Utilizou-se o delineamento em parcelas subdivididas com três repetições distribuídas ao acaso, sendo as parcelas constituídas pelos sistemas de cultivo e as sub-parcelas pelas espécies vegetais de sucessão.

Para controle das invasoras durante o ciclo das diferentes culturas agrícolas e sistemas de manejo estudados, quando necessário, utilizou-se capina através de enxada nos cultivos mínimo e convencional e herbicida no sistema plantio direto.

\section{Análise do solo}

Para determinação da densidade do solo e posterior avaliação do estoque de carbono, foram utilizados anéis de metal bizelados, nas camadas de 0-10 e 10-20 cm, nas subparcelas das culturas em sucessão, onde as amostras de solo, após coletadas foram retiradas dos anéis e acondicionadas em cápsulas de alumínio previamente identificadas e encaminhadas ao laboratório para serem colocadas na estufa a $105{ }^{\circ} \mathrm{C}$ por $24 \mathrm{~h}$ e depois pesadas (EMBRAPA, 1997).

Para a determinação do Carbono Orgânico Total, realizou-se a coleta de amostras deformadas de solo, na área útil de cada parcela cultivada com milho, nas posições linha e entrelinha, em duas profundidades $(0-10$ e 10-20 cm). Sub-amostras de terra fina seca ao ar (TFSA) foram trituradas e passadas em peneira $(2 \mathrm{~mm})$ para determinação do teor de COT pelo método de oxidação por via úmida, com aquecimento externo (YEOMANS; BREMNER, 1988). Segundo o referido método, a
MOS é oxidada com uma mistura de $\mathrm{K}_{2} \mathrm{Cr}_{2} \mathrm{O}_{7} 0,167$ mol L-1 e $\mathrm{H}_{2} \mathrm{SO}_{4}$ concentrado, sendo o excesso de dicromato titulado com sulfato ferroso amoniacal. Assume-se que o dicromato reduzido durante a reação com o solo equivale ao carbono orgânico na amostra de solo (GATTO et al., 2009).

O nitrogênio total foi determinado através do método de Kjeldahl, baseado em digestão sulfúrica e destilação (EMBRAPA, 1997).

O estoque de carbono em cada uma das camadas amostradas foi estimado a partir da expressão:

$$
\mathrm{E}=(\mathrm{C} \times \mathrm{Ds} \mathrm{x} \text { e }) / 10(\text { CARDOSO et al., 2010), }
$$

em que E é o estoque de carbono em $\mathrm{Mg} \mathrm{ha}^{-1}$; C indica o teor de Carbono orgânico total em $\mathrm{g} \mathrm{kg}^{-1}$; Ds é a Densidade do solo do horizonte estudado em $\mathrm{kg} \mathrm{dm}^{-3} \mathrm{e}$ "e" é a espessura da camada em $\mathrm{cm}$.

Para avaliar o efeito dos sistemas de preparo do solo e das plantas de sucessão sobre as características avaliadas, os dados coletados e obtidos foram submetidos à análise de variância e, em seguida, as médias comparadas pelo teste de Tukey ao nível de $5 \%$ de probabilidade.

Para a realização da análise estatística, utilizouse o programa estatístico Sisvar (FERREIRA, 2003).

\section{Resultados e Discussão}

As plantas de cobertura e sistemas de manejo influenciaram o teor de carbono total, nas duas profundidades avaliadas, como pode ser verificado nos resultados apresentados a seguir. No sistema convencional na profundidade de $0-10 \mathrm{~cm}$, o amendoim foi significativamente superior a crotalária, enquanto na profundidade de $10-20 \mathrm{~cm}$, os teores de COT apresentaram efeitos significativos quando se comparou os grupos de plantas de sucessão, amendoim, feijão e guandu em relação a crotalária (Figura 1A). 
Figura 1. Concentração de carbono orgânico total de um Argissolo Vermelho Amarelo, nas profundidades de 0-10 e 10-20 cm em função de plantas de cobertura nos sistemas de plantio convencional (A), mínimo (B) e direto (C), cultivado com milho nos Tabuleiros Costeiros de Sergipe. Médias seguidas pela mesma letra minúscula na coluna e maiúscula na linha não diferem entre si pelo teste de Tukey, a 5\% de probabilidade. São Cristóvão, SE, 2010.

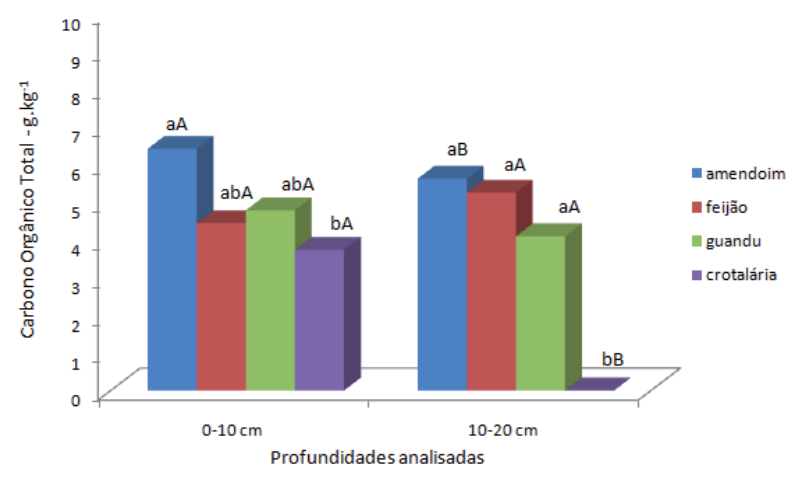

(A)

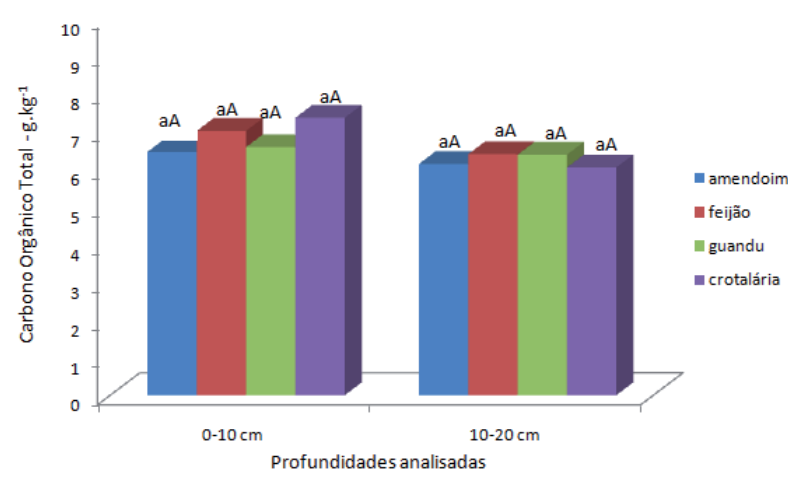

(B)

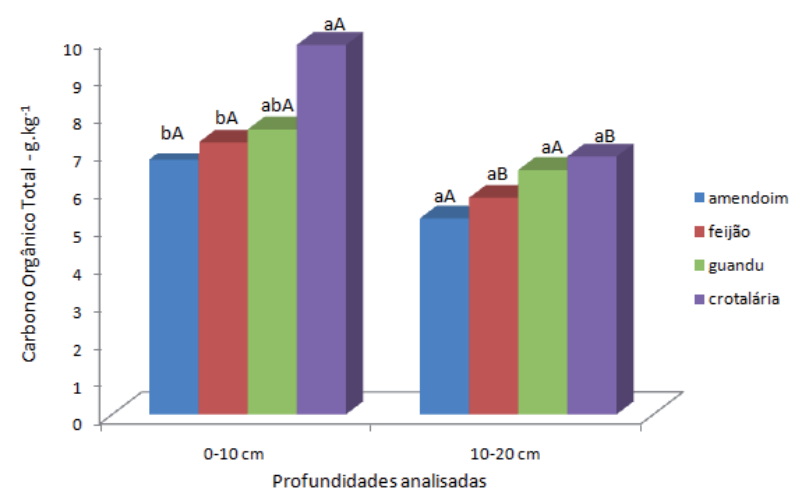

(C)

Fonte: Elaboração dos autores.

Segundo Quaggio e Godoy (1997), a cultura do amendoim é dispensada da prática de adubação nitrogenada em plantio. Por sua vez aproveita bem o efeito residual de adubações anteriores, sendo excelente em rotação de culturas, na seqüência de culturas anteriormente adubadas. Segundo
Moreira e Siqueira (2002) esse efeito residual de $\mathrm{N}$ de culturas anteriores serve como uma dose de arranque favorecendo a FBN.

Quando se utilizou o sistema de cultivo mínimo, os teores de COT não obteve efeito significativo nem dentro e nem entre as profundidades estudadas (Figura 
1B). Para o sistema sem revolvimento do solo, o sistema plantio direto verifica-se que na profundidade superficial $(0-10 \mathrm{~cm})$, o uso da crotalária, como cultura de sucessão ao milho doce proporcionou superioridade no teor de COT, enquanto na camada subsuperficial não se verificou efeito das plantas de sucessão sobre os teores de COT.

A possível explicação para os maiores valores de carbono no solo cultivado com crotalária pode estar no fato de que esta planta disponibiliza nitrogênio à cultura do milho, o que ocasiona em aumento da biomassa que retorna ao solo como aporte de carbono no plantio direto. Assim, o cultivo de adubos verdes pode favorecer outras culturas em rotação ou sucessão, e, também, com o tempo, incrementar o teor de matéria orgânica do solo, o qual está diretamente relacionado com a adição de $\mathrm{N}$ ao solo, seja pela fixação biológica, seja por meio da adição de fertilizantes minerais ou orgânicos (AMADO; MIELNICZUK; AITA, 2002).

Mas, quando se compara os teores de COT entre as profundidades estudadas, nota-se que a utilização do feijão e da crotalária proporcionou superioridade nos teores de COT na profundidade de $0-10 \mathrm{~cm}$ em relação a 10-20 cm (Figura 1C). O motivo para tais comportamentos está na localização superficial dos resíduos culturais reduz o contato solo-resíduo, retardando a decomposição. Outros efeitos, tais como: não-fracionamento mecânico dos resíduos, menor temperatura, maior umidade, menor aeração do solo e preservação dos agregados superficiais, contribuem para menor taxa de mineralização do N orgânico (AMADO; MIELNICZUK; FERNANDES, 2000).

De acordo com Duda et al. (2003), que avaliaram o efeito de diferentes leguminosas nos teores de COT sob Argissolo Vermelho Amarelo, verificaram que o uso de adubos verdes pode proporcionar um aumento nos teores de COT. Esses autores observaram que a manutenção dos resíduos das leguminosas após cada corte promoveu ampliação nos teores COT, enfatizando a importância da utilização dessa prática para melhorar a fertilidade do solo.
A crotalária está no grupo das plantas com a mais baixa razão $\mathrm{C} / \mathrm{N}$ do material verde, o que também pode explicar essa decomposição bastante elevada no início do processo, sobretudo no manejo com incorporação dos resíduos pela elevada concentração de $\mathrm{N}$ na parte aérea (CARVALHO et al., 2008).

Quando se leva em consideração os teores de COT nos sistemas de preparo do solo, para as profundidades de 0-10 e 10-20 cm observa-se que na profundidade superficial, os sistemas de preparo do solo, mínimo e plantio direto proporcionaram teores significativamente superiores aos do sistema convencional (Figura 2).Comportamento semelhante foi observado para o teor de COT na profundidade de $10-20 \mathrm{~cm}$. Na comparação dos sistemas de preparo do solo entre as profundidades verificou-se que os sistemas, convencional e plantio direto proporcionaram os maiores teores de COT na profundidade de 0-10 cm (Figura 2).

No cultivo convencional, as práticas de manejo realizadas parecem favorecer a quebra dos agregados e desta forma promover uma maior oxidação da matéria orgânica (PINHEIRO; PEREIRA; ANJOS, 2003).

Com relação ao estoque de COT em função das plantas de sucessão e as profundidades estudadas, pode-se afirmar que na profundidade de $0-10 \mathrm{~cm}$, o estoque de COT não diferiu significativamente entre as plantas de sucessão utilizadas, enquanto na profundidade de $10-20 \mathrm{~cm}$, o uso de culturas de sucessão, feijão, amendoim e guandu proporcionaram os maiores estoques de COT em comparação ao uso da crotalária (Tabela 1). Quando se faz a comparação do estoque de COT entre as profundidades observou-se que independente das espécies vegetais utilizadas, como culturas de sucessão, os teores de COT foram significativamente superiores na profundidade de 10-20 cm (Tabela 1). Isso pode ser explicado porque o feijão guandu é uma leguminosa de sistema radicular profundo e eficiente na ciclagem de nutrientes (NUNES, 2006). 
Figura 2. Concentração de Carbono orgânico total de um Argissolo Vermelho Amarelo, nas profundidades de 0-10 e 10-20 cm, em função dos sistemas de plantio convencional, mínimo e direto, cultivado com milho nos Tabuleiros Costeiros de Sergipe. Médias seguidas pela mesma letra minúscula na coluna e maiúscula na linha não diferem entre si pelo teste de Tukey, a 5\% de probabilidade. São Cristóvão, SE, 2010.

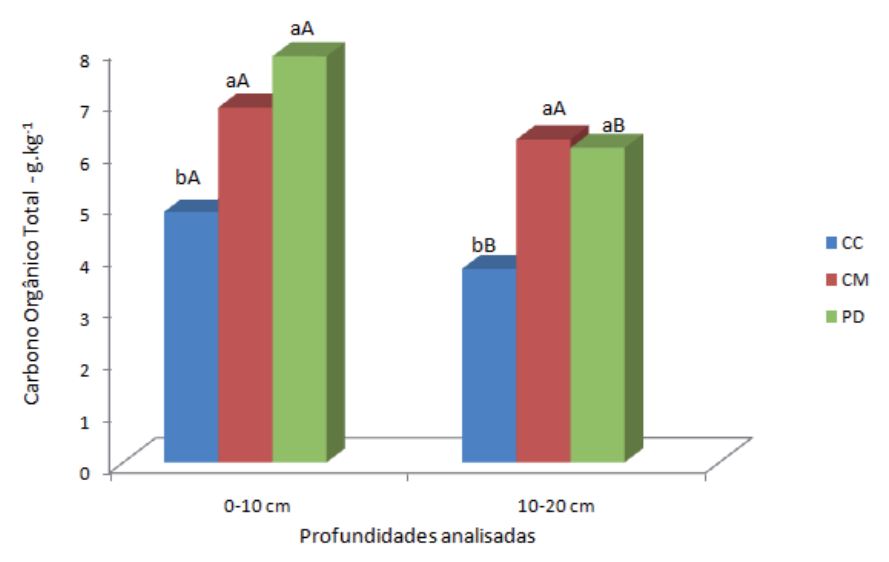

Fonte: Elaboração dos autores.

Tabela 1. Estoque médios de carbono em função das plantas de sucessão/milho nas profundidades avaliadas.

\begin{tabular}{ccc}
\hline Plantas de Sucessão & Estoque de C \\
\hline & $0-10 \mathrm{~cm}$ & $10-20 \mathrm{~cm}$ \\
Feijão & $9,22 \mathrm{aB}^{1}$ & $16,85 \mathrm{aA}$ \\
Amendoim & $9,58 \mathrm{aB}$ & $16,73 \mathrm{aA}$ \\
Guandu & $9,16 \mathrm{aB}$ & $18,75 \mathrm{aA}$ \\
Crotalária & $10,11 \mathrm{aB}$ & $13,11 \mathrm{bA}$ \\
\hline
\end{tabular}

${ }^{1}$ Letras diferentes minúsculas na vertical e maiúsculas na horizontal diferem estatisticamente pelo teste de Tukey ao nível de 5\% de probabilidade.São Cristóvão, SE, 2010.

Fonte: Elaboração dos autores.

Quanto aos maiores valores apresentados na camada de 10-20 cm (Tabela 1), esse fato pode ser explicado em virtude do experimento já possuir 9 anos, essa relação foi também confirmada em trabalhos realizados por Bayer et al. (2000); Sá et al. (2001); Lovato et al. (2004), que verificaram aumentos na quantidade de $\mathrm{C}$ mais significativos nas camadas superficiais do solo, nos anos iniciais do sistema plantio direto, mas com o tempo, os estoques aumentaram nas camadas mais profundas. Outra explicação pode ser decorrente da textura do solo, pois de modo geral, solos mais argilosos apresentam menores taxas de mineralização do carbono (MENDHAM; CONNELL; GROVE,
2002) e, conseqüentemente, maiores teores de COT, enquanto que maiores perdas são observadas nas frações texturais mais grosseiras (RAWLS et al., 2003).

As frações mais grosseiras possuem menor proteção coloidal do carbono, pois segundo Neves, Connell e Grove (2005), há a perda do material orgânico da fração areia dado à maior labilidade, à suscetibilidade, à oxidação e à desintegração dos resíduos vegetais e hifas de fungos presentes nessa fração.

A utilização de leguminosas em sistemas de rotação de culturas é uma eficiente estratégia de manutenção/recuperação dos estoques de carbono 
do solo. Segundo Pontelli et al. (2010) a inclusão de leguminosas em sucessão ao milho proporciona um aumento em $10 \%$ no estoque de carbono.

O tempo de implantação do plantio direto e a sucessão de culturas promoveram alterações nos estoques de COT no perfil do solo, apresentando diferença significativa entre os sistemas de cultivo e as profundidades avaliadas (Tabela 2). Nas camadas de 0-10 e 10-20 cm, o CM e o PD foram superiores com relação ao estoque de carbono, diferindo estatisticamente do CC. Os resultados baixos para o estoque de COT no CC possivelmente foram devido ao revolvimento do solo.

Tabela 2. Estoque médios de carbono em função dos sistemas de manejo nas profundidades avaliadas.

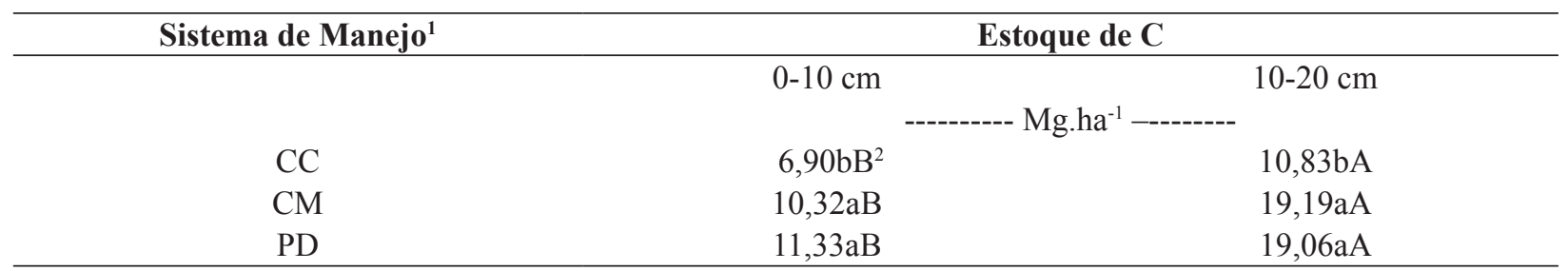

${ }^{1} \mathrm{CC}$-cultivo contínuo (gradagem+aração+gradagem); CM - cultivo mínimo (grade); PD - plantio direto (sem cultivo). ${ }^{2}$ Letras diferentes minúsculas na vertical e maiúsculas na horizontal diferem estatisticamente pelo teste de Tukey ao nível de $5 \%$ de probabilidade. São Cristóvão, SE, 2010.

Fonte: Elaboração dos autores.

Albuquerque et al. (2005) observaram que o acúmulo de $\mathrm{C}$ no preparo reduzido, ao longo do tempo, favorecem um maior acúmulo de matéria orgânica no solo em relação ao plantio convencional. Isso é decorrente do maior aporte de resíduos e do menor revolvimento do solo presentes no PD, conforme observado em diversos estudos (LEITE et al., 2003; BAYER et al., 2006; CARVALHO et al., 2008).

$\mathrm{Na}$ avaliação dos sistemas de manejo entre as duas profundidades, a camada de 10-20 cm apresentou resultados superiores com relação à camada de 0-10 cm, quanto ao estoque de carbono (Tabela 2).

Os métodos de preparo do solo e plantas de sucessão influenciaram significativamente os estoques de carbono no solo. Os menores valores foram encontrados no CC (Tabela 2). Esse comportamento pode ser explicado em função deste sistema de manejo apresentar uma distribuição uniforme da matéria orgânica no perfil do solo, em virtude da inversão da camada superficial e da incorporação dos resíduos durante a aração e dessa forma, as perdas de C são intensificadas pelo aumento da atividade microbiana devido à exposição da superfície e fratura dos agregados, oxigenação do ambiente interno do solo, favorecimentos de acúmulo de maior quantidade de calor na camada superficial revolvida e sem cobertura (AMORIM et al., 2010).

Dentro do CC, o solo que foi cultivado com feijão, amendoim e guandu diferiu significativamente do solo com crotalária, quanto ao estoque de carbono. No CM, não houve diferença estatística entre as espécies, já no PD as plantas de cobertura apresentaram diferenças significativas quanto ao estoque de carbono.

Comparando-se os valores apresentados entre os sistemas de manejo, o solo cultivado com feijão e amendoim apresentou maiores valores dentro do sistema de manejo mínimo. Já o guandu e a crotalária forneceram maiores aportes de carbono no sistema de manejo do sistema de plantio direto (Tabela 3). Possivelmente, decorrente da maior quantidade de biomassa, que essas espécies vegetais utilizadas como culturas de sucessão apresentaram. 
Tabela 3. Estoque médios de carbono em função das plantas de sucessão/milho e dos sistemas de manejo, nas profundidades avaliadas.

\begin{tabular}{lccl}
\hline \multicolumn{1}{c}{ Plantas de Sucessão } & \multicolumn{3}{c}{ Estoque de C } \\
\hline & $\mathrm{CC}$ & $\mathrm{CM}$ & $\mathrm{PD}$ \\
Feijão & & $-----{\mathrm{Mg} \cdot \mathrm{ha}^{-1}---}$ & \\
Amendoim & $10,57 \mathrm{aB}^{1}$ & $15,09 \mathrm{aA}$ & $13,45 \mathrm{bAB}$ \\
Guandu & $10,60 \mathrm{aB}$ & $15,20 \mathrm{aA}$ & $13,67 \mathrm{bAB}$ \\
Crotalária & $11,65 \mathrm{aB}$ & $14,42 \mathrm{aAB}$ & $15,7 \mathrm{abA}$ \\
\hline
\end{tabular}

Letras diferentes minúsculas na vertical e maiúsculas na horizontal diferem estatisticamente pelo teste de Tukey ao nível de 5\% de probabilidade. São Cristóvão, SE, 2010.

Fonte: Elaboração dos autores.

Com relação ao nitrogênio total, o solo cultivado com as espécies avaliadas não apresentou diferença significativa dentro do sistema convencional (Figura 3A). No sistema de manejo mínimo, dentro da profundidade de $0-10 \mathrm{~cm}$, não houve diferença significativa nos valores de nitrogênio total (3B). No entanto, na profundidade de $10-20 \mathrm{~cm}$, as plantas de sucessão amendoim, guandu e crotalária proporcionaram maiores aportes de nitrogênio em comparação ao feijão. Entre as profundidades, somente a planta feijão apresentou diferença significativa (Figura 3B).

Os menores valores apresentados no solo cultivado com feijão, pode ser devido à baixa produção de matéria seca quando comparado às outras espécies, ou à fixação de nitrogênio pouco eficiente nesta espécie (VIEIRA; PAULA JÚNIOR; TEIXEIRA, 2010).

No sistema de manejo plantio direto, dentro da profundidade de $0-10 \mathrm{~cm}$, não houve diferença significativa, no entanto na profundidade de 10$20 \mathrm{~cm}$, as plantas de sucessão amendoim, guandu e crotalária proporcionaram maiores aportes de nitrogênio com relação à planta feijão.Avaliando entre as profundidades, somente a planta feijão apresentou diferença significativa entre as profundidades, com valores inferiores na camada de 10-20 cm (Figura 3C). Quanto aos valores de NT presentes nos sistemas, observa-se que o CM e PD apresentaram maiores resultados na profundidade de 0-10 cm, em comparação ao CC (Figura 4). Isso pode ser explicado pelo menor revolvimento do solo, o que acarreta em maior aporte de nutrientes devido à baixa taxa de oxidação da matéria orgânica (AMADO; MIELNICZUK; AITA, 2002).

Na profundidade de 10-20 $\mathrm{cm}$ o CM apresentou maiores resultados, diferindo estatisticamente dos sistemas CC e PD.Entre as duas profundidades, apenas o PD diferiu estatisticamente, proporcionando um maior aporte $C$ na profundidade de $0-10 \mathrm{~cm}$.

Com relação ao estoque de nitrogênio do solo, as plantas de sucessão não proporcionaram diferença significativa, dentro das duas profundidades avaliadas (Tabela 4). No entanto, entre as profundidades houve diferença significativa, sendo que a camada de 10-20 $\mathrm{cm}$ apresentou os maiores valores de estoque de nitrogênio. Esse fato pode ser decorrente da idade do experimento e segundo Bayer et al. (2000), em longo prazo, o acúmulo de matéria orgânica pode ocorrer também em maiores profundidades no solo ou pela textura do solo.

Mesmo não apresentando diferença significativa entre as espécies analisadas, o solo cultivado com guandu foi o que apresentou maiores valores na camada de 10-20 cm (Tabela 4), esse fato ocorreu segundo Valarini e Godoy (1994) devido a capacidade de colaborar com a Fixação Biológica de Nitrogênio (FBN), pois as plantas de guandu que sofrem nodulação tem mais de $90 \%$ do $\mathrm{N}$ sucedido da simbiose. 
Figura 3. Concentração do nitrogênio total do solo de um Argissolo Vermelho Amarelo nas profundidades de $0-10$ e 10-20 cm, em função de plantas de cobertura nos sistemas de plantio convencional (A), mínimo (B) e direto (C). Médias seguidas pela mesma letra minúscula na coluna, dentro de cada profundidade e maiúscula, comparando as culturas de sucessão entre as profundidades diferem entre si pelo teste de Tukey, a 5\% de probabilidade. São Cristóvão, SE, 2010.

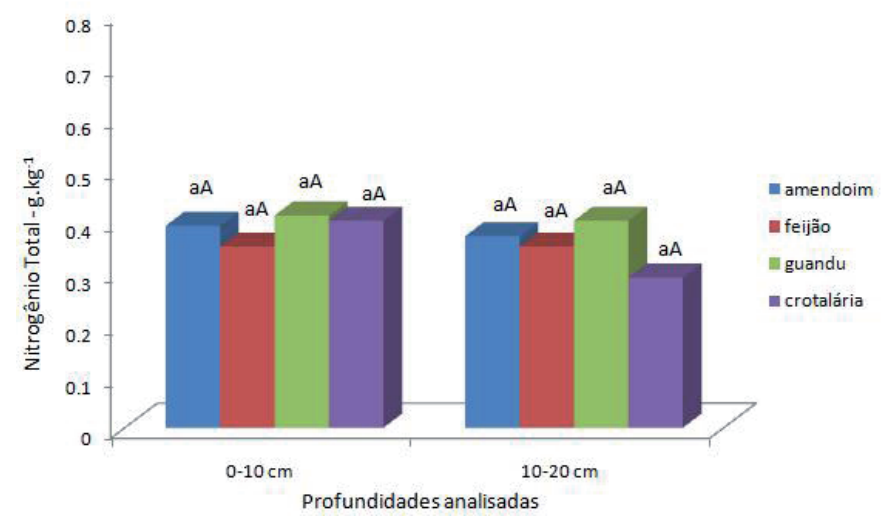

(A)

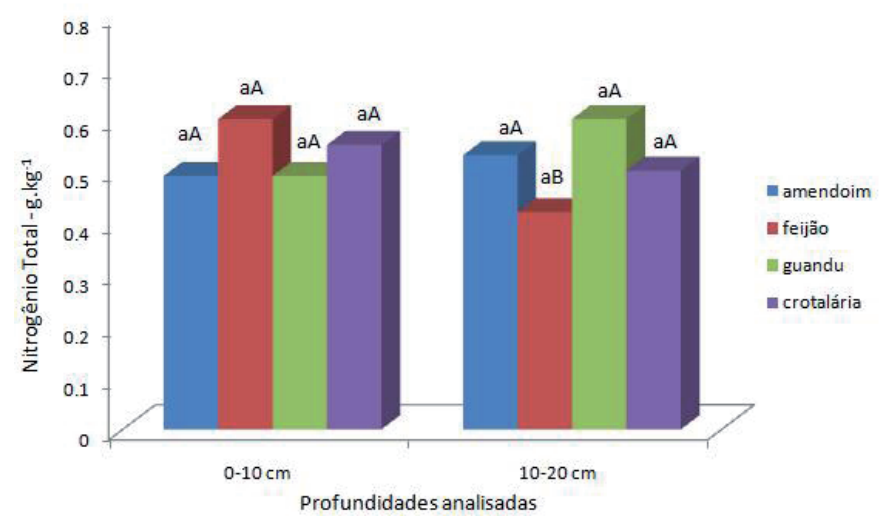

(B)

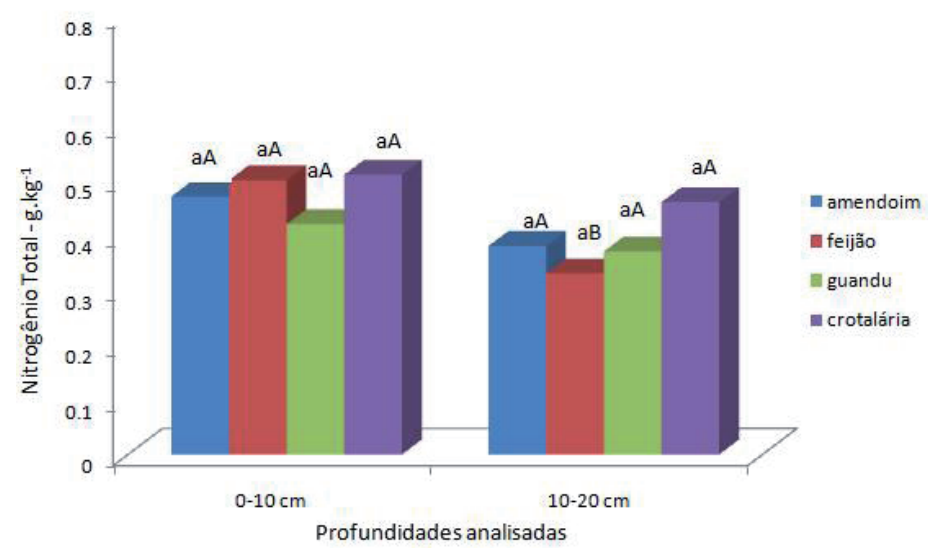

(C)

Fonte: Elaboração dos autores. 
Figura 4. Concentração do nitrogênio total do solo de um Argissolo Vermelho Amarelo nas profundidades de 0-10 e 10-20 cm, em função dos sistemas de plantio. Médias seguidas pela mesma letra minúscula na coluna, dentro de cada profundidade e maiúscula, comparando os sistemas de preparo do solo entre as profundidades não diferem entre si pelo teste de Tukey, a 5\% de probabilidade. São Cristóvão, SE, 2010.

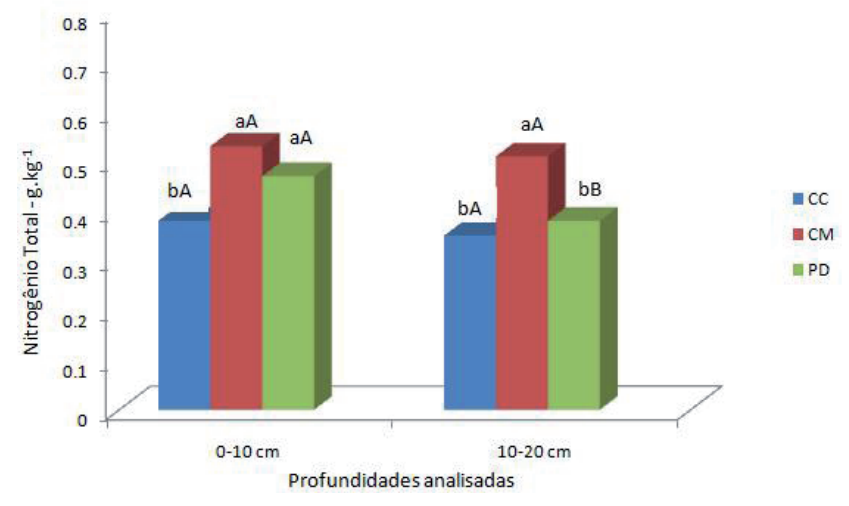

Fonte: Elaboração dos autores.

Tabela 4. Estoque médio de nitrogênio em um Argissolo Vermelho-Amarelo em função das plantas de sucessão/milho nas profundidades de $0-10$ e $10-20 \mathrm{~cm}$.

\begin{tabular}{ccc}
\hline Plantas de Sucessão & Estoque de N \\
\hline & $0-10 \mathrm{~cm}$ & $10-20 \mathrm{~cm}$ \\
Feijão & $0,70 \mathrm{aB}^{1}$ & $1,09 \mathrm{aA}$ \\
Amendoim & $0,65 \mathrm{aB}$ & $1,32 \mathrm{aA}$ \\
Guandu & $0,63 \mathrm{aB}$ & $1,37 \mathrm{aA}$ \\
Crotalária & $0,69 \mathrm{aB}$ & $1,24 \mathrm{aA}$ \\
\hline
\end{tabular}

${ }^{1}$ Letras diferentes minúsculas na vertical e maiúsculas na horizontal diferem estatisticamente pelo teste de Tukey ao nível de $5 \%$ de probabilidade. São Cristóvão, SE, 2010.

Fonte: Elaboração dos autores.

Amado et al. (1999) demonstraram que a utilização de leguminosas por longo tempo, além de aumentar o estoque de $\mathrm{N}$, aumenta a capacidade de fornecimento de $\mathrm{N}$ do solo às culturas comerciais. O sistema de manejo mínimo apresentou maiores valores de estoque de $\mathrm{N}$ nas duas profundidades avaliadas (Tabela 5), diferenciando-se significativamente dos outros sistemas de manejo. Entre as profundidades, todos os sistemas de manejo apresentaram diferenças significativas, sendo que na camada de 10-20 foram encontrados maiores valores de estoque de N. Já Amado et al. (2001) encontraram maiores valores no PD.
Entre os sistemas, todas as plantas proporcionaram diferenças significativas quanto ao estoque de nitrogênio, sendo que os maiores resultados foram encontrados no sistema de manejo mínimo (Tabela 6). Existe uma relação entre os estoques de $\mathrm{C}$ e $\mathrm{N}$ no solo; por esse motivo, para obter maior eficiência em seqüestrar C no solo, há necessidade de haver periódicas adições de N. Uma estratégia econômica e ambientalmente sustentável para adicionar $\mathrm{N}$ é a utilização de leguminosas em sistemas de rotação de culturas (AMADO et al., 2001). 
Tabela 5. Estoque médios de nitrogênio em um Argissolo Vermelho-Amarelo em função dos sistemas de manejo nas profundidades de $0-10$ e $10-20 \mathrm{~cm}$.

\begin{tabular}{|c|c|c|}
\hline Sistema de Manejo ${ }^{1}$ & \multicolumn{2}{|c|}{ Estoque de $\mathrm{N}$} \\
\hline & $0-10 \mathrm{~cm}$ & $10-20 \mathrm{~cm}$ \\
\hline$C C$ & $054 \mathrm{hR}^{2}$ & $100 \mathrm{bA}$ \\
\hline $\mathrm{CM}$ & $0,79 \mathrm{aB}$ & $1,56 \mathrm{aA}$ \\
\hline PD & $0,68 \mathrm{abB}$ & $1,20 \mathrm{bA}$ \\
\hline
\end{tabular}

${ }^{1} \mathrm{CC}$-cultivo contínuo (gradagem+aração+gradagem); CM - cultivo mínimo (grade);PD - plantio direto (sem cultivo). ${ }^{2}$ Letras diferentes minúsculas na vertical e maiúsculas na horizontal diferem estatisticamente pelo teste de Tukey ao nível de $5 \%$ de probabilidade. São Cristóvão, SE, 2010.

Fonte: Elaboração dos autores.

Tabela 6. Estoque médios de nitrogênio em um Argissolo Vermelho-Amarelo em função das plantas de sucessão/ milho e sistemas de manejo.

\begin{tabular}{lccc}
\hline \multicolumn{1}{c}{ Plantas de Sucessão } & \multicolumn{2}{c}{ Estoque de N } \\
\hline & $\mathrm{CC}$ & $\mathrm{CM}$ & $\mathrm{PD}$ \\
Feijão & $0,73 \mathrm{aB}^{1}$ & $1,09 \mathrm{aA}$ & $0,88 \mathrm{aAB}$ \\
Amendoim & $0,81 \mathrm{aB}$ & $1,25 \mathrm{aA}$ & $0,91 \mathrm{aB}$ \\
Guandu & $0,86 \mathrm{aB}$ & $1,25 \mathrm{aA}$ & $0,89 \mathrm{aB}$ \\
Crotalária & $0,68 \mathrm{aB}$ & $1,13 \mathrm{aA}$ & $1,08 \mathrm{aA}$ \\
\hline
\end{tabular}

${ }^{1}$ Letras diferentes minúsculas na vertical e maiúsculas na horizontal diferem estatisticamente pelo teste de Tukey ao nível de $5 \%$ de probabilidade. São Cristóvão, SE, 2010.

Fonte: Elaboração dos autores.

$\mathrm{Na}$ tabela 7, pode-se verificar que as plantas de sucessão amendoim, guandu e crotalária proporcionaram maiores valores na relação $\mathrm{C} / \mathrm{N}$ na profundidade de $0-10 \mathrm{~cm}$, diferindo estatisticamente do feijão. Já na segunda profundidade avaliada, de 10-20 cm, o feijão forneceu mais carbono ao solo, em comparação à demais plantas.Entre as profundidades avaliadas, todas as espécies proporcionaram diferenças estatísticas.

Tabela 7. Relação $\mathrm{C} / \mathrm{N}$ em um Argissolo Vermelho-Amarelo em função das plantas de sucessão/milho nas profundidades de $0-10$ e $10-20 \mathrm{~cm}$.

\begin{tabular}{cll}
\hline Plantas de Sucessão & \multicolumn{1}{c}{$\mathbf{C} / \mathbf{N}$} & \\
\hline & $0-10 \mathrm{~cm}$ & $10-20 \mathrm{~cm}$ \\
Feijão & $13,17 \mathrm{bB}^{1}$ & $15,45 \mathrm{aA}$ \\
Amendoim & $14,73 \mathrm{aA}$ & $12,67 \mathrm{bB}$ \\
Guandu & $14,53 \mathrm{aA}$ & $13,68 \mathrm{bAB}$ \\
Crotalária & $14,65 \mathrm{aA}$ & $10,57 \mathrm{cB}$ \\
\hline
\end{tabular}

${ }^{1}$ Letras diferentes minúsculas na vertical e maiúsculas na horizontal diferem estatisticamente pelo teste de Tukey ao nível de $5 \%$ de probabilidade. São Cristóvão, SE, 2010.

Fonte: Elaboração dos autores. 
Comparando-se os sistemas de manejo estudados, nas duas profundidades avaliadas, observa-se que o
PD proporcionou um maior aporte de carbono ao solo, por apresentar uma maior relação $\mathrm{C} / \mathrm{N}$ que os demais sistemas (Tabela 8).

Tabela 8. Relação C/N em um Argissolo Vermelho Amarelo em função dos sistemas de manejo nas profundidades de $0-10$ e $10-20 \mathrm{~cm}$.

\begin{tabular}{ccc}
\hline${\text { Sistema de } \text { Manejo }^{\mathbf{1}}}$ & $\mathbf{C} / \mathbf{N}$ & \\
\hline & $0-10 \mathrm{~cm}$ & $10-20 \mathrm{~cm}$ \\
$\mathrm{CC}$ & $12,77 \mathrm{bA}$ & $10,83 \mathrm{cB}$ \\
$\mathrm{CM}$ & $13,06 \mathrm{bA}$ & $12,30 \mathrm{bA}$ \\
PD & $16,66 \mathrm{aA}$ & $15,88 \mathrm{aA}$ \\
\hline
\end{tabular}

${ }^{1} \mathrm{CC}$-cultivo contínuo (gradagem+aração+gradagem); CM - cultivo mínimo (grade);PD - plantio direto (sem cultivo). ${ }^{2}$ Letras diferentes minúsculas na vertical e maiúsculas na horizontal diferem estatisticamente pelo teste de Tukey ao nível de $5 \%$ de probabilidade. São Cristóvão, SE, 2010.

Fonte: Elaboração dos autores.

Os resultados apresentados quanto à relação $\mathrm{C} / \mathrm{N}$ é condizente com a literatura, pois as leguminosas apresentam menor relação $\mathrm{C} / \mathrm{N}$, formando um material que apresenta uma relação $\mathrm{C} / \mathrm{N}$ menor que a de equilíbrio $(<28 / 1)$, sendo desta forma um material que durante a decomposição libera nitrogênio para a cultura implantada em sucessão sobre os restos culturais (DIEKOW et al., 2005).

Com base nos resultados, supõe-se que o processo de mineralização de nutrientes irá se sobrepor ao de imobilização, devido à baixa relação C/N apresentada (DONEDA, 2010).

\section{Conclusões}

Os resultados referentes ao Plantio Direto demonstraram que houve um maior incremento do carbono orgânico total em comparação aos outros sistemas de manejo.

Os sistemas Plantio Direto e Cultivo Mínimo foram os que mais contribuíram para o aumento dos teores de nitrogênio total no solo.

As plantas de cobertura feijão, amendoim e guandu proporcionaram maiores estoques de carbono, dentro do sistema Plantio Direto. No
Cultivo Mínimo o guandu proporcionou maiores estoques de nitrogênio.

Os sistemas Plantio Direto e Cultivo Mínimo apresentaram os maiores estoques de carbono e nitrogênio respectivamente, em comparação ao Cultivo convencional, contribuindo para uma melhor sustentabilidade agrícola.

\section{Agradecimentos}

À Fundação de Apoio à Pesquisa e à Inovação Tecnológica do Estado de Sergipe (FAPITEC), pela bolsa concedida à primeira autora.

\section{Referências}

ALBUQUERQUE, J. A.; ARGENTON, J.; BAYER, C.; WILDNER, L. P.; KUNTZE, M. A. G. Relação de atributos do solo com a agregação de um latossolo vermelho sob sistemas de preparo e plantas de verão para cobertura do solo. Revista Brasileira de Ciência do Solo, Viçosa, MG, v. 29, n. 3, p. 415-424, 2005.

AL-KAISI, M. M.; YIN, X. Tillage and crop residue effects on soil carbon and carbon dioxide emission in corn-soybean rotations. J. Environ. Qual., Madison, v. 34, n. 2, p. 437-445, 2005. 
AMADO, T. J. C.; MIELNICZUK, J.; FERNANDES, S. B. V. Leguminosas e adubação mineral como fontes de nitrogênio para o milho em sistemas de preparo do solo. Revista Brasileira de Ciência do Solo, Viçosa, MG, v. 24, n. 1, p. 179-189, 2000.

AMADO, T. J. C.; BAYER, C.; ELTZ, F. L. F.; BRUM, A. C. R. Potencial de culturas de cobertura em acumular carbono e nitrogênio no solo no plantio direto e a melhoria da qualidade ambiental. Revista Brasileira de Ciência do Solo, Viçosa, MG, v. 25, n. 1, p. 189-197, 2001.

AMADO, T. J. C.; MIELNICZUK, J.; AITA, C. Recomendação de adubação nitrogenada para o milho no RS e SC adaptada ao uso de culturas de cobertura do solo, sob plantio direto. Revista Brasileira de Ciência do Solo, Viçosa, MG, v. 26, n. 1, p. 241-248, 2002.

AMADO, T. J. C.; MIELNICZUK, J.; FERNANDES, S. B. V.; BAYER, C. Culturas de cobertura, acúmulo de nitrogênio total no solo e produtividade de milho. Revista Brasileira de Ciência do Solo, Viçosa, MG, v. 23, n. 1, p. 679-686, 1999.

AMORIM, R. S. S.; SILVA, D. D.; PRUSKI, F. F.; MATOS, A. T. Avaliação do desempenho dos modelos de predição da erosão hídrica USLE e WEPP para diferentes condições edafoclimáticas do Brasil. Engenharia Agrícola, Jaboticabal, v. 30, n. 6, p. 1046-1049, 2010.

BAYER， C.; MIELNICZUK, J.; MARTIN-NETO, L.; ERNANI, P. R. Stocks and humification degree of organic matter fractions as affected by no-tillage on a subtropical soil. Plant and Soil, The Hague, v. 238, n. 1, p. 133-140, 2002.

BAYER, C.; SPAGNOLLO, E.; WILDNER, L. P.; ERNANI, P. R.; ALBURQUEQUE, J. A. Incremento de carbono e nitrogênio num latossolo pelo uso de plantas estivais para cobertura do solo. Ciência Rural, Santa Maria, v. 33, n. 3, p. 469-475, 2003.

BAYER, C.; MARTIN-NETO, L.; MIELNICZUK, J.; PAVINATO, A.; DIECKOW, J. Carbon sequestration in two Brazilian Cerrado soils under no-till. Soil Tillage Research, Amsterdam, v. 86, n. 2, p. 237-245, 2006.

BAYER, C.; MIELNICZUK, J.; AMADO, T. J. C.; MARTIN-NETO, L.; FERNANDES, S. V. Organic matter storage in a sandy clay loam Acrisol affected by tillage and cropping systems in southern Brazil. Soil Tillage Research, Amsterdam, v. 54, n. 1, p. 101-109, 2000.

BERNOUX, M.; CARVALHO, M. C. S.; VOLKOFF, B.; CERRI, C. C. CO2 emission from mineral soils following land-cover change in Brazil. Global Change Biology, Urbana, v. 7, n. 1, p. 779-787, 2006.
CARDOSO, E. L.; SILVA, M. L. N.; SILVA, C. A.; CURI, N.; FREITAS, D. A. F. de. Estoques de carbono e nitrogênio em solo sob florestas nativas. Pesquisa Agropecuária Brasileira, Brasília, v. 45, n. 9, p. 10281035, 2010.

CARVAlHO, J. L. N.; CERRI, C. E. P.; FEIGL, B. J.; PICCOLO, M. C.; GODINHO, V. P.; CERRI, C. C. Carbon sequestration in agricultural soils in the Cerrado region of the Brazilian Amazon. Soil Tillage Research, Amsterdam, v. 103, n. 1, p. 342-349, 2008.

CERRI, C. E. P.; SPAROVEK, G.; BERNOUX, M.; EASTERLING, W. E.; MELILLO, J. M.; CERRI, C. C. Tropical agriculture and global warming: impacts and mitigation options. Scientia Agricola, Piracicaba, v. 64, n. 1, p. 83-99, 2007.

DIEKOW, J.; CERETTA, C. A.; GONÇALVES, C. N.; MARCOLAN, A. L. Influência da relação $c / n$ de plantas de cobertura do solo e adubação nitrogenada no rendimento de grãos de milho. 2005. Disponível em: $<$ www.ufsm.br/ppges/congressos/XXVI_Congresso. 2005>. Acesso em: 02 dez. 2010.

DONEDA, A. Plantas de cobertura de solo consorciadas e em cultivo solteiro: decomposição e fornecimento de nitrogênio ao milho. 2010. Dissertação (Mestrado em Ciência do Solo) - Universidade Federal de Santa Maria, Santa Maria.

DUDA, G. P.; GUERRA, J. G. M.; MONTEIRO, M. T.; DE-POLLI, H. Perennial herbaceous legumes as live soil mulches and their effects on $\mathrm{C}, \mathrm{N}$ and $\mathrm{P}$ of the microbial biomass. Scientia Agricola, Piracicaba, v. 60, n. 1, p. 139-147, 2003.

EMPRESA BRASILEIRA DE PESQUISA AGROPECUÁRIA - EMBRAPA SOLOS. Sistema brasileiro de classificação de solos. 2. ed. Rio de Janeiro, 2006. 306 p.

Manual de métodos de análise de solo. 2. ed. Rio de Janeiro, 1997. 212 p.

FERREIRA, D. F. Sisvar versão 4.2. DEX/UFLA, 2003.

GATTO, A.; BARROS, N. F. de; FERREIRA NOVAIS, R.; RIBEIRO SILVA, I.; SÁ MENDONÇA, E. de; ALBUQUERQUE VILLANI, E. M. de. Comparação de métodos de determinação do carbono orgânico em solos cultivados com eucalipto. Revista Brasileira de Ciência do Solo, Viçosa, MG, v. 33, n. 3, p. 735-740, 2009.

HAVSTAD, K. M.; PETERS, D. P. C.; SKAGGS, R.; BROWN, J.; BESTELMEYER, B.; FREDRICKSON, E.; HERRICK, J.; WRIGHT, J. Ecological services to and from rangelands of the United States. Ecological Economics, Boston, v. 64, n. 2, p. 261-268, 2007. 
LAL, R. Soil carbon sequestration impacts on global climate change and food security. Science, Washington, v. 304, n. 5677, p. 1623-1627, 2004.

LEITE, L. F. C.; MENDONÇA, E. S.; MACHADO, P. L. O. A.; MATOS, E. S. Total C and N storage and organic C pools of a Red-Yellow Podzolic under conventional and no tillage at the Atlantic Forest Zone, Southeastern Brazil. Australian Journal of Soil Research, Victoria, v. 41, n. 4, p. 717-730, 2003.

LORENZ, K.; LAL, R.; PRESTON, C. M.; NIEROP, K. G. J. Strengthening the soil organic carbon pool by increasing contributions from recalcitrant aliphatic bio(macro)molecules. Geoderma, Amsterdam, v. 142, n. 1, p. 1-10, 2007.

LOVATO, T.; MIELNICZUK, J.; BAYER, C.; VEZZANI, F. Adições de carbono e nitrogênio e sua relação com os estoques no solo e com o rendimento do milho em sistemas de manejo. Revista Brasileira de Ciência do Solo, Viçosa, MG, v. 28, n. 1, p. 175-187, 2004.

MACHADO, P. O. Carbono do solo e a mitigação da mudança climática global. Química Nova, São Paulo, v. 28, n. 2, p. 239-334, 2005.

MEEHL, G. A.; STOCKER, T. F.; COLLINS, W. D.; FRIEDLINGSTEIN, P. Global climate projections. In: SOLOMON, S. D. et al. (Ed.). Climate change 2007: the physical science basis. Contribution of working group i to the fourth assessment report of the intergovernmental panel on climate change. Cambridge: University Press, 2007.

MENDHAM, D. S.; CONNELL, A. M.; GROVE, T. S. Organic matter characteristics under native forest, long-term pasture, and recent conversion to eucalyptus plantations in Western Australia: microbial biomass, soil respiration, and permanganate oxidation. Australian Journal of Soil Science, Camberra, v. 40, n. 5, p. 859872, 2002.

MOREIRA, F. M.; SIQUEIRA, J. O. Microbiologia e bioquímica do solo. Lavras: Universidade Federal de Lavras, 2002. $625 \mathrm{p}$.

NEVES, S. V. J.; FELLER, C.; LARRÉ-LARROY, M. C. Matéria orgânica nas frações granulométricas de um latossolo vermelho sob diferentes sistemas de uso e manejo. Semina: Ciencias Agrárias, Londrina, v. 26, n. 1, p. 17-26, 2005.
NUNES, H. V. Plantio direto e decomposição de restos culturais em diferentes sistemas de cultivo. 2006. Tese (Doutorado em Agronomia) - Universidade Federal da Paraíba, Areia.

PINHEIRO, E. F. M.; PEREIRA, M. G.; ANJOS, L. H. C. Aggregate distribution and soil organic matter under different tillage systems for vegetable crops in a Red Latosol from Brazil. Soil Tillage Research, Amsterdam, v. 77, n. 1, p. 79-84, 2003.

PONTELLI, C. B.; AMADO, T. J. C.; CONCEIÇÃO, P. C.; JÚNIOR, G. G.; ROSSATO, R. R.; PEDROSO, M. T. Dinâmica da matéria orgânica em sistemas de cultura do milho em argissolo vermelho distrófico. 2002. Disponível em: <w3.ufsm.br/ppgcs/congressos/ XIVReuniãoBrasileiraCuiabá/37. . . Acesso em: 25 out. 2010.

QUAGGIO, J. A.; GODOY, I. J. Leguminosas e oleaginosas. In. RAIJ, B. (Ed.). Recomendações de adubação e calagem para o Estado de São Paulo. Campinas: IAC, 1997. p. 192. (Boletim técnico, 100).

QUEIROZNETO, C.V.Corte manual dá sustentabilidade à cana-de-açúcar. [S.1.:s.n.], 2006.

RAWLS, W. J.; PACHEPSKY, Y. A.; RITCHIE, J. C.; SOBECKI, T. M.; BLOODWORTH, H. Effect of soil organic carbon on soil water retention. Geoderma, Amsterdam, v. 116, n. 1, p. 61-76, 2003.

SÁ, J. C. M.; CERRI, C. C.; DICK, W. A.; LAL, R.; VENZKE FILHO, S. P.; PICCOLO, M. C.; FEIGL, B. J. Organic matter dynamics and carbon sequestration rates for a tillage chronosequence in a Brazilian Oxisol. Soil Science Society American Journal, Madison, v. 65, n. 1, p. 1486-1499, 2001.

SWIFT, R. S. Sequestration of carbon by soil. Soil Science, Madison, v. 166, n. 11, p. 858-871, 2001.

VALARINI, M. J.; GODOY, R. Contribuição da fixação simbiótica de nitrogênio na produção do guandu (Cajanus cajan (L.) Millsp). Nova Odessa, SP: Instituto de Zooctenia, 1994.

VIEIRA, R. F.; PAULA JÚNIOR, T. J.; TEIXEIRA, H. Produção de feijão: segurança alimentar. Informe Agropecuário, Belo Horizonte, v. 31, n. 1, p. 22-27, 2010.

YEOMANS, J. C.; BREMNER, J. M. A rapid and precise method for routine determination of organic carbon in soil. Comm. Soil Science. Plant Anal., Philadelphia, v. 19, n. 13, p. 1467-1476, 1988. 
